\title{
The effect of THIP on the thermal and mechanical thresholds of chronic sciatic nerve cuff injury mice.
}

\author{
$\underline{\text { Saya Hakata }}{ }^{\text {a)}}$, Ayako Takahashi ${ }^{a}$, Akira Iuraa), Seiichi Osakoa), Hironobu Uematsua), Yuji Fujino ${ }^{\text {a) }}$ \\ a)Department of Anesthesiology and Intensive Care medicine, Osaka University Graduate School of Medicine
}

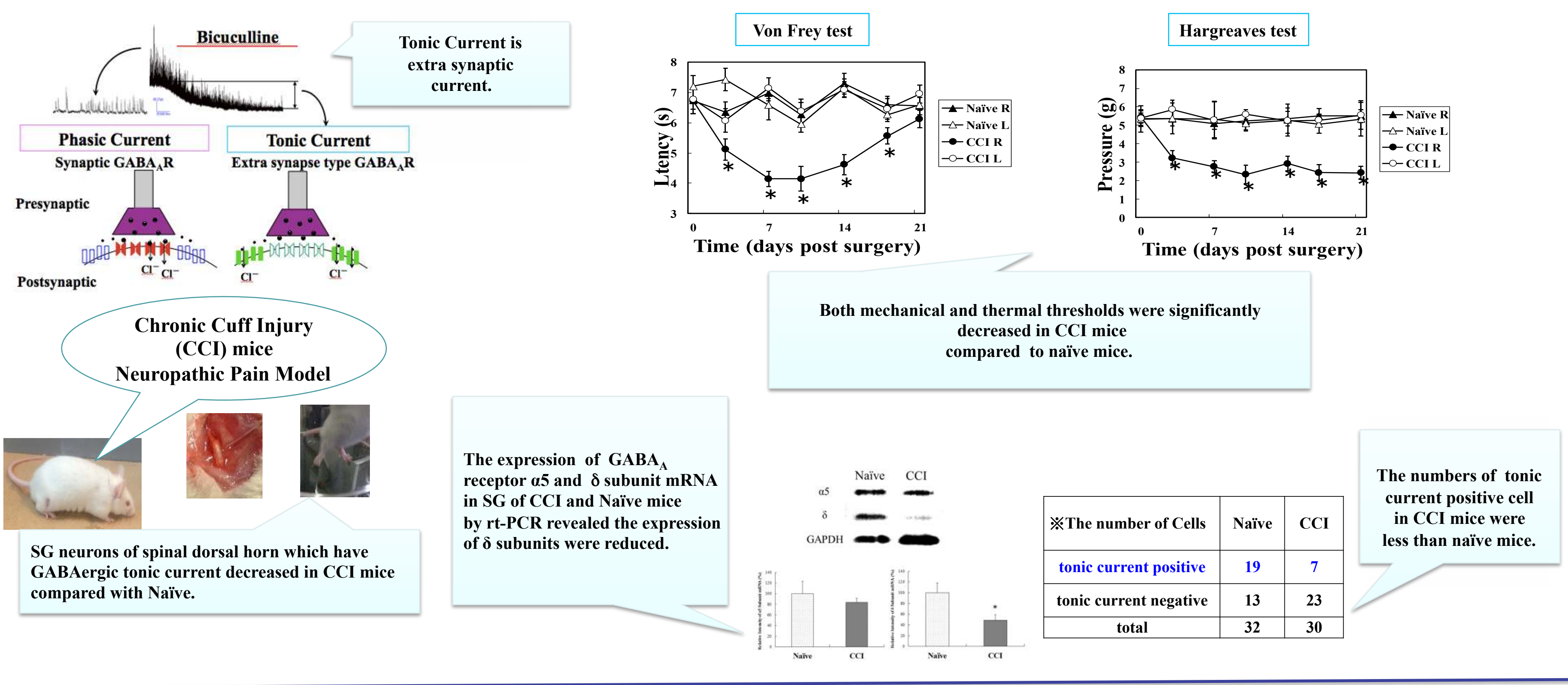

\section{Introduction}

Decreased Gamma-aminobutyric acid (GABA)-ergic phasic inhibitory transmission in the spinal cord is thought to be responsible for the development of neuropathic pain. However, the role of GABAergic tonic current in neuropathic pain is unknown. We and others previously reported that a subset of substantia gelatinosa (SG) neurons of the dorsal horn of the spinal cord possess GABAergic tonic current mediated by $\mathrm{GABA}_{\mathrm{A}}$ receptor $\left(\mathrm{GABA}_{\mathrm{A}} \mathrm{R}\right) \mathrm{s}$ containing the $\mathrm{a} 5, \mathrm{~d}$ subunits. Recently, $\mathrm{GABA}_{\mathrm{A}} \mathrm{R} \delta$ subunit preferring agonists 4,5,6,7tetrahydroisoxazolo [5,4-c]pylidine-3-ol (THIP) has been reported effective to reduce acute thermal pain in normal mice. We have suggested that the $\delta \mathrm{GABA}_{\mathrm{A}} \mathrm{R}$ mediated tonic current in dorsal horn also plays an important role in the mechanism of neuropathic pain. In this study, we assessed the effect of $\mathrm{GABA}_{\mathrm{A}} \mathrm{R} \delta$ subunit antagonist on the pain thresholds of chronic constriction injury (CCI) mice, a neuropathic pain model mice.

\section{Methods}

Male ddY mice (4 weeks age) were anesthetized with 3\% sevoflurane, a 2-mm long split section of polyethylene tubing (PE-20) was placed around the nerve to induce chronic constriction injury (CCI). To measure pain threshold, we evaluated the mechanical paw withdrawal thresholds and the latency of thermal stimulation by von Frey and Hargreaves tests. Two weeks after surgery, we made intrathecal administration of $\delta \mathrm{GABA}_{\mathrm{A}} \mathrm{R}$ preferring agonists $\mathrm{THIP}(0.7 \mu \mathrm{g}$ i.t. $)$ $(\mathrm{N}=15)$ or normal saline $(\mathrm{NS})(\mathrm{N}=15)$ by double blinds methods, and analyzed the effect on the thresholds of mechanical and thermal stimulation.

\section{Results}

CCI mice showed both mechanical and thermal allodynia. Thermal hypersensitivity disappeared by 3 weeks post-surgery, on the other hand, mechanical hypersensitivity continued more than three weeks as in a previous study.

Intrathecal administration of THIP induced significantly improved both thermal $(4.6 \pm 0.8$ to $6.6 \mathrm{~s} \pm 1.1 \mathrm{~s}:$ pre to post $)$ and mechanical $(2.6 \pm 0.9 \mathrm{~g}$ to $5.6 \pm 1.6 \mathrm{~g}$ ) thresholds ( $<<0.05$, non-paired $\mathrm{t}$-test). On the other hand, NS did not effect on both thermal $(4.2 \pm 0.9 \mathrm{~s}$ to $4.3 \pm 1.2 \mathrm{~s})$ and mechanical $(3.1 \pm 0.5 \mathrm{~g}$ to $3.7 \pm 1.0 \mathrm{~g})$ thresholds.

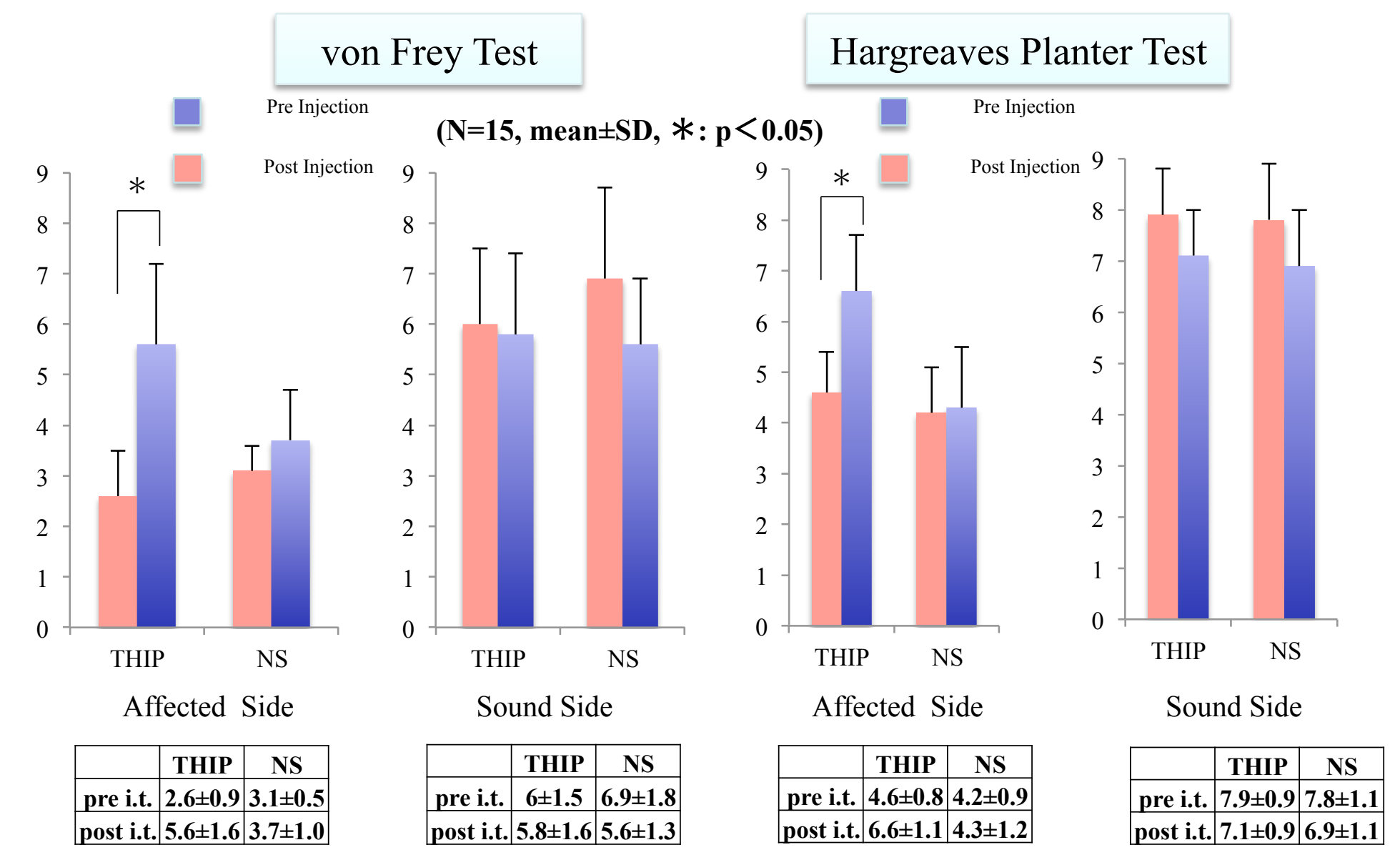

Conclusion

THIP showed effective on both thermal and mechanical hypersensitivity. This might be suggested that $\delta \mathrm{GABA}_{\mathrm{A}} \mathrm{R}$ mediated tonic current in the spinal cord contribute to the mechanism of neuropathic pain.

\section{Discussion}

THIP showed effective on both thermal and mechanical hypersensitivity. In the previous study, THIP showed therapeutic effects on acute pain of mice. ${ }^{1)}$ Our study might be suggested that $\delta \mathrm{GABA}_{\mathrm{A}} \mathrm{R}$ mediated tonic current in the spinal cord contribute to the mechanism of neuropathic pain.

Our result suggests that $\mathrm{GABA}_{\mathrm{A}} \mathrm{R} \delta$ subunit-mediated tonic currents may likewise be a therapeutic target for neuropathic pain.

Refferences

1) R.P.Bonin et al. PAIN. 2011 